

\title{
Compact Wide-Angle Scanning Multibeam Antenna Array for V2X Communications
}

Muhammad Kamranishfaq, Suleiman Aliyu Babale, Hassan Tariq Chattha, Mohamed Himdi, Ali Raza, Muhammad Younas, Tharek Abd. Rahman, Sharul Kamal Abdul Rahim, Bilal Khawaja

\section{To cite this version:}

Muhammad Kamranishfaq, Suleiman Aliyu Babale, Hassan Tariq Chattha, Mohamed Himdi, Ali Raza, et al.. Compact Wide-Angle Scanning Multibeam Antenna Array for V2X Communications. IEEE Antennas and Wireless Propagation Letters, 2021, 19 (1), pp.1-1. 10.1109/LAWP.2021.3100349 . hal-03325751

\section{HAL Id: hal-03325751 \\ https://hal.science/hal-03325751}

Submitted on 8 Sep 2021

HAL is a multi-disciplinary open access archive for the deposit and dissemination of scientific research documents, whether they are published or not. The documents may come from teaching and research institutions in France or abroad, or from public or private research centers.
L'archive ouverte pluridisciplinaire $\mathbf{H A L}$, est destinée au dépôt et à la diffusion de documents scientifiques de niveau recherche, publiés ou non, émanant des établissements d'enseignement et de recherche français ou étrangers, des laboratoires publics ou privés. 


\title{
Compact Wide-Angle Scanning Multibeam Antenna Array for V2X Communications
}

\author{
Muhammad K. Ishfaq ${ }^{1}$, Suleiman. A Babale², Hassan T. Chattha ${ }^{3}$, M. Himdi $^{4}$, Ali Raza ${ }^{1}$, M. Younas ${ }^{1}$, \\ Tharek. A. Rahman ${ }^{5}$, Sharul Kamal A. Rahim ${ }^{5}$, Bilal A. Khawaja ${ }^{3}$
}

\begin{abstract}
This paper presents a wide-angle scanning multibeam Planar Inverted-E Antenna (PIEA) array for V2X communication. The compact 4-element PIEA array is designed with $0.3 \lambda_{0}$ spacing, which achieves $90^{\circ}$ wide-angle scanning when a $135^{\circ}$ phase shift is applied obtained using a 4x4 Butler matrix (BM). The closeness of the array elements causes high mutual coupling and high crosspolarization at wider scan angles. Therefore, three novel techniques are employed to overcome the high cross-polarization and mutual coupling between antenna elements in this array. To feed the antenna array, a low-cost miniaturised beamforming 4x4 Butler matrix (BM) circuit is designed without the use of phase shifters and conventional crossovers. The total dimensions of the compact PIEA array are just $0.456 \lambda_{0} \times 1.12 \lambda_{0} \times 0.036 \lambda_{0}$ while the overall dimensions of the multi-beam array including Butler Matrix are $2.731 \lambda_{0} \times 2.2 \lambda_{0}$ $x 0.046 \lambda_{0}$. This multi-beam array achieves for the first time the wide-angle scanning angles of $\pm 87^{\circ}$ with a 3 -dB beam scanning range of $\pm 120^{\circ}$ along with the scanning angles of $\pm 20^{\circ}$. This array design can be scaled to use as an antenna array for mm-wave applications.
\end{abstract}

Index Terms - PIEA Array, Wide-angle Scanning, Mutual coupling, Butler Matrix, Modified Coupler, Phase shifter, V2X

\section{INTRODUCTION}

$\mathrm{T}$ he driverless cars and the autonomous driving features in vehicles have greatly increased the interest in Vehicle to everything (V2X) communications (Fig. 1). At present, V2X communication is relying on Dedicated Short-Range Communication (DSRC) $5.9 \mathrm{GHz}(5.85-5.925 \mathrm{GHz})$ band [12]. In the future, cellular-vehicle to everything (C-V2X) communication will make use of readily available $5 \mathrm{G}$ infrastructure at sub- $6 \mathrm{GHz}, 28 \mathrm{GHz}$ and $39 \mathrm{GHz}$ bands [3]. To bring V2X to fruition, wide coverage antennas, MIMO, compact switched beam arrays and beamforming arrays are the key enabling antenna technologies [3,4]. The Switch Beamforming Network (SBFN), which is an arrangement of antenna array capable of generating a highly directive beam and steer it to desired directions [5]. There are several types of SBFN, such as the Blass matrix [6], the Rotman lens [7], the Nolen matrix [8], and the Butler matrix (BM) [9]. The most].

Muhammad Kamran Ishfaq, Ali Raza and Muhammad Younas are with Electrical Engineering and Computer Science Departments, Government College University Faisalabad, Pakistan. Suleiman Aliyu Babale is with Department of Electrical Engineering, Bayero University, Kano, Nigeria. Hassan Tariq Chattha and Bilal A. Khawaja are with Department of Electrical Engineering, Faculty of Engineering, Islamic University of Madinah, Saudi Arabia. Mohammed Himdi is with Institut d'Electronique et des Technologies du numéRique (IETR), UMR CNRS 6164, University of Rennes I, France. Tharek. A. Rahman and Sharul Kamal Abd. Rahim are with Wireless Communication Center, University Teknologi Malaysia. popular among these techniques is BM for having a relatively simple configuration and low-power dissipations [10-13

For designing compact arrays, mutual coupling severely degrades the performance of the beamforming arrays [14]. The research works in [14],[17] present compact designs but have a limited scanning range using high-cost phase shifters. The design in [15] is a compact phased array using high-cost phase shifters, but it had limited scanning and very high crosspolarization around $0 \mathrm{~dB}$ at $70^{\circ}$ scan-angle making it unable to be used for wide-angle scanning. The research in [16] presented a wide-angle scanning array using reconfigurable pattern elements with a scanning range of $\pm 75^{\circ}$. However, the design is not compact (spacing, 1.2 $\lambda$ ).

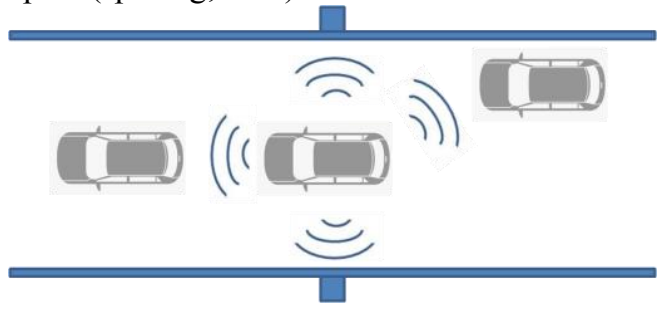

Figure 1: Vehicle-to-Vehicle (V2V) communication example

This work presents a low cost, miniaturized compact multibeam wide-angle scanning array at DSRC $5.9 \mathrm{GHz}$ band for V2X communication. Since compact arrays suffer from high mutual coupling [14] and high cross-polarization at wider scan angles [15]. Therefore, to mitigate mutual coupling and high cross-polarization, three novel techniques are employed, which include employing a reduced size PIEA, etching long slots inbetween adjacent array elements, and designing and placing two decoupling meandered line structures in-between the adjacent array elements. To feed the antenna array, a miniaturized BM is designed without the use of phase shifters and classical crossovers. Hence, for the first time, the far beam is achieved at $\pm 87^{\circ}$ using the novel compact wide-angle scanning multibeam PIEA array proposed with $0.3 \lambda_{0}$ spacing. The array design can also be scaled to mm-wave as presented in [18].

\section{WIDE ANGLE SCANNING ARRAY DESIGN}

A PIEA array is designed with a $0.3 \lambda_{0}$ spacing to achieve wide-angle scanning. Using PIEA (a modified dual shorting PIFA) as an array element results in reduced mutual coupling due to the formation of a naturally formed slot antenna inbetween the neighboring array elements [19]. However, it suffers from high cross-polarization and poor gain at wider scanning angles [15]. Thus, to overcome high cross- 
polarization and high mutual coupling, the following design procedure/techniques are employed:

(i) As a first step, the single PIEA is designed with the compact structure having reduced width to accommodate the increased inter-corner spacing, $S e$, while maintaining spacing to $0.3 \lambda_{0}$. It helps in reducing radiations due to the naturally formed slot antenna in-between the two adjacent antenna elements.

(ii) To reduce mutual coupling the slots having width $S e$, are etched in the ground plane in-between each of the two adjacent array elements. It reduces the coupling current between the two adjacent antennas.

(iii) To further reduce mutual coupling and crosspolarization, two decoupling Meandered Line (ML) structures possessing high inductive reactance are introduced at distances $Y_{S 2}$ and $Y_{C 2}$ from the PIEA corner, in the slots in-between each of the two adjacent array elements, as shown in Fig. 2(c). The ML-structure detailed dimensions are zoomed-in in Fig. 2(c).

To feed the antenna array using BM, a feeding mechanism is designed. All the array elements are fed by a $50-\Omega$ microstrip feed line $\left(L_{f 2} \times W_{f 2}\right)$, etched at $L_{f 1}$, as shown in Fig. 2(b). The copper of the feed-side ground blocks the slots and decoupling ML structure. To avoid blockage and any variation in the impedance of ML structures, all the copper is etched except which is precisely below the feed line (i.e. $L_{f 2} \times W_{f 2}$ as shown in Fig. 2(c)).

Fig. 2 shows the 3D and back view of the proposed compact antenna array having four PIEA elements. Figure 2 (a) shows the configuration of a single element. Roger RT/Duroid 3003 $\left(\varepsilon_{r}=3\right)$ is used as the dielectric material (thickness, $t=0.25$ $\mathrm{mm})$. Table-1 shows the optimized values of the design parameters of the array.

The $S_{11} \& S_{22}<-10 \mathrm{~dB}$ in Fig. 3 (a) indicate that the array is performing well from $5.3 \mathrm{GHz}$ to $6.75 \mathrm{GHz}$. While the mutual couplings $S_{12} \& S_{23}<-10 \mathrm{~dB}$ show that the techniques employed have effectively suppressed the mutual coupling. The current distribution in Fig. 3 (b) shows that the decoupling ML structure exhibits a high inductance, which reduces the mutual coupling. While the opposite current flowing in the meandered line structure cancels out the radiations, which helps to minimize the cross-polarization.

TABLE I: OPTIMIZED Design VALUES OF PIEA ARRAY

\begin{tabular}{cccc}
\hline \hline Parameter & $\begin{array}{c}\text { Value } \\
(\mathbf{m m})\end{array}$ & Parameter & $\begin{array}{c}\text { Value } \\
(\mathbf{m m})\end{array}$ \\
\hline$W_{c 2}$ & 0.5 & $L_{f 1}$ & 2.5 \\
$W_{=} W_{G}$ & 11 & $d_{e}$ & 15 \\
$L_{G}$ & 22.8 & $S e$ & 4 \\
$W_{S}$ & 1 & $L_{f 2}$ & 12.5 \\
$W_{f}$ & 6 & $L_{g t l}$ & 2.5 \\
$L$ & 8.5 & $L_{g t 2}$ & 8.61 \\
$h$ & 1.8 & $W_{2}$ & 0.26 \\
$L_{S}$ & 1 & $W_{3}$ & 0.95 \\
$W_{f 2}$ & 0.615 & $W_{4}$ & 1.31 \\
$Y_{C 2}$ & 16 & $W_{5}$ & 0.15 \\
$Y_{S 2}$ & 0.04 & $t$ & 0.25 \\
$W g_{-}$array & 56 & $\lambda_{0}(5.9 \mathrm{GHz})$ & 50.8 \\
\hline
\end{tabular}

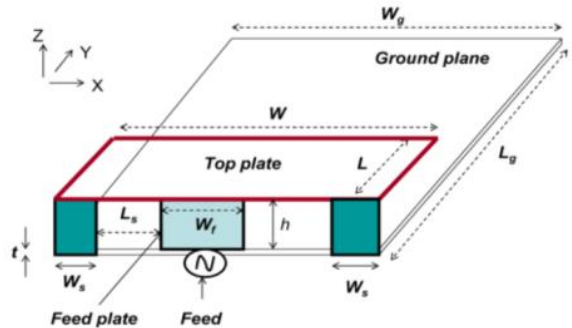

(a)

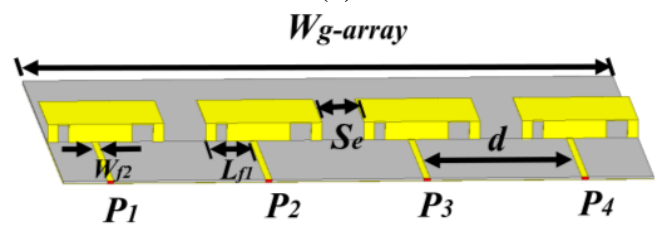

(b)

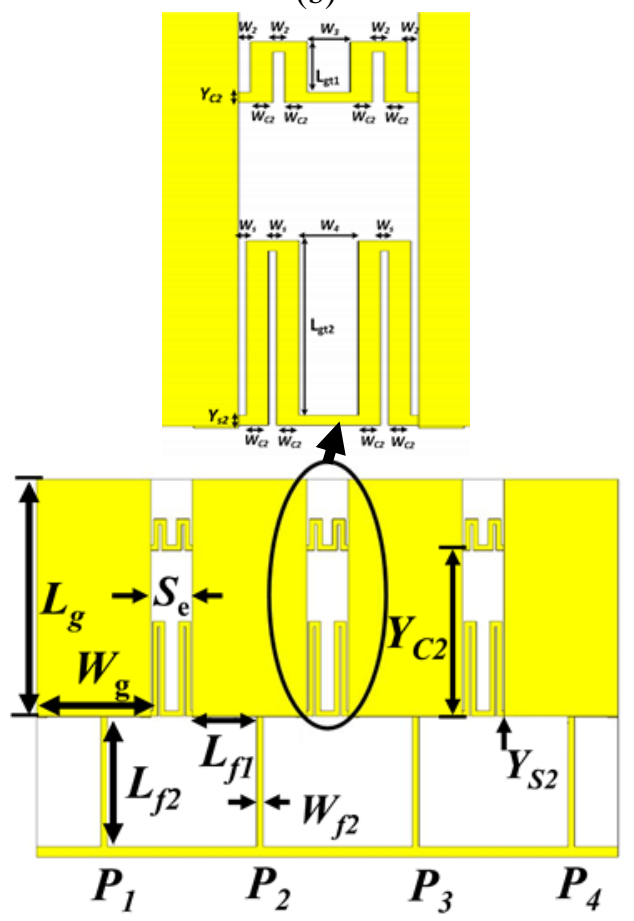

(c)

Figure 2: Planar Inverted-E Antenna (PIEA) Array (a) Single Element, (b)Array Top with feeding Part(c) Array Ground plane with Zoom in Highlighting the Decoupling Structure

\section{BUTLER MATRIX DESIGN}

Generally, 4x4 BM consists of $90^{\circ}$ couplers, $45^{\circ}$ phase shifters, and crossovers by combining two $90^{\circ}$ couplers [10]. In this work, the BM without phase shifters is designed using the cross-coupled crossover. The $4 \times 4 \mathrm{BM}$ presented in this paper utilizes only the microstrip couplers and a crossover in a planar structure. Employing the modified $45^{\circ}$ couplers in this design eliminate the use of phase shifters [20]. This reduces the dimension and transmission loss of the device by shortening the transmission line path, thus reducing the problem of insertion loss and reducing the number of components required in forming BM. The layout of the BM is shown in Fig. 4. 


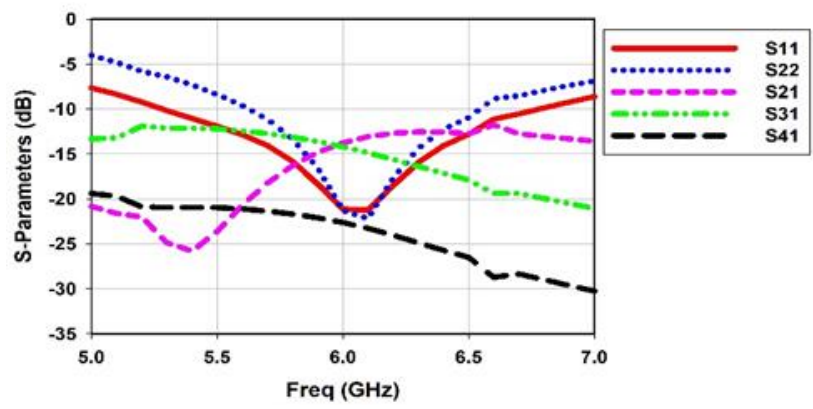

(a)

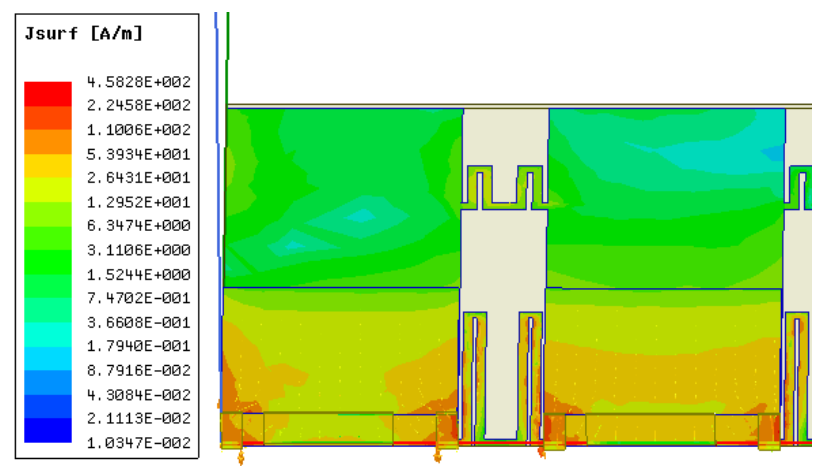

(b)

Figure 3: Planar Inverted-E Antenna (PIEA) Array (a) SParameters (dB), (b) Current Distribution

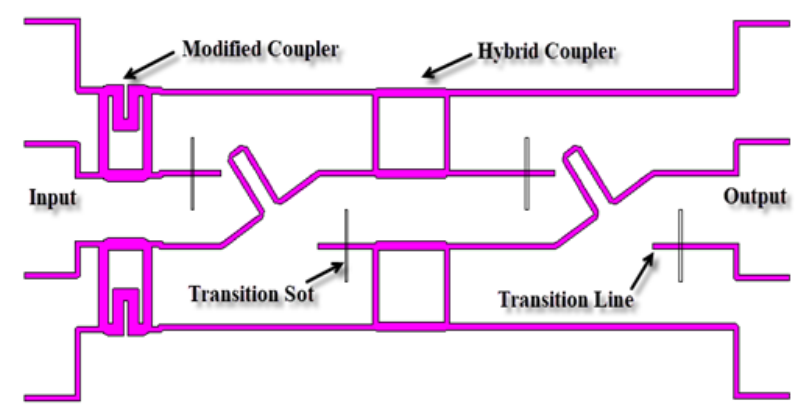

Figure 4: Layout of the cross-coupled BM

Fig. 5(a) shows the reflection coefficient and transmission coefficients when port 1 of the BM is energized. Likewise, Fig. 5 (b) shows the $\mathrm{S}$-parameters when port 2 of the BM is energized while the remaining three ports are terminated with a $50 \mathrm{ohms}$ load. Similarly, due to the symmetry of the BM, exciting ports 3 and 4 have a similar effect as ports 2 and 1 respectively. From Fig.5(c), it can also be seen that the progressive phase difference at the outputs of the BM are $+45^{0},-135^{\circ},+135^{\circ}$, and $-45^{0}$ at the operating frequency, when ports $1,2,3$, and 4 are excited respectively. This conforms with the theoretical values.

\section{FABRICATION AND MEASUREMENTS}

The proposed multibeam wide-angle scanning PIEA array design was excited using the $4 \times 4$ BM designed in section III and the overall system was tested and measured in an anechoic chamber. Fig. 6 shows the complete fabricated prototype of the multibeam antenna array. Fig. 7 shows the simulated and measured S-parameters of the compact multibeam PIEA array when Port-1 is fed. Between 5.5 to $6.3 \mathrm{GHz}$, the reflection coefficients and port isolations are below $<-10 \mathrm{~dB}$, which confirms that the multibeam array performs well for DSRC 5.9 $\mathrm{GHz}$ band. When Port 2 and 3 of the BM are excited, the main pattern radiates at an angle of $\pm 20^{\circ}$ with a cross-polarization < $18 \mathrm{~dB}$, and when the power is excited at ports 1 and 4 , the angle switches to $\pm 87^{0}$ with a cross-polarization $<-13 \mathrm{~dB}$. The output radiation patterns are depicted in Fig. 8. Both the measurements and the simulation results matched with little disparity due to fabrication limitations. Most of the $4 \times 4$ BM multibeam array literature shows the multibeam at $\pm 14^{\circ}$ and $\pm 48^{\circ}$ [9], [10], while this design radiates multibeam at $\pm 20^{\circ}$ and $\pm 87^{\circ}$. The reason for this wide scanning angle using $4 \times 4 \mathrm{BM}$ is because of the closeness of the array spacing to $0.3 \lambda_{0}$, achieved by employing the novel techniques to effectively reduce mutual coupling and cross-polarization.

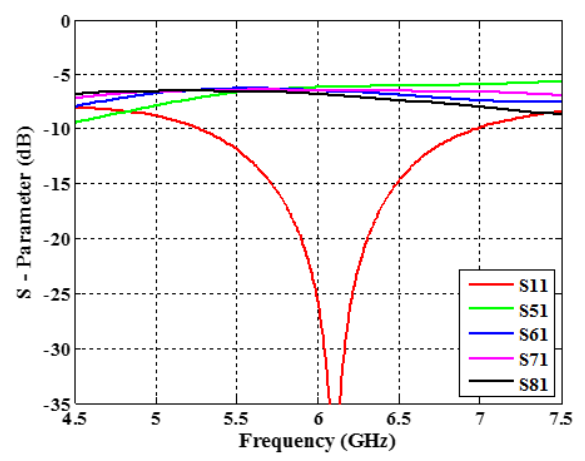

(a)

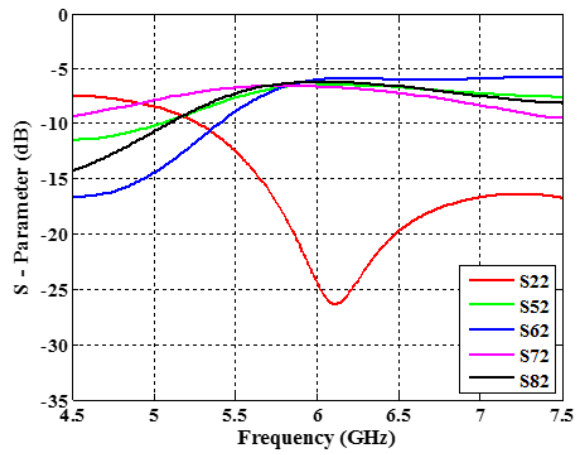

(b)

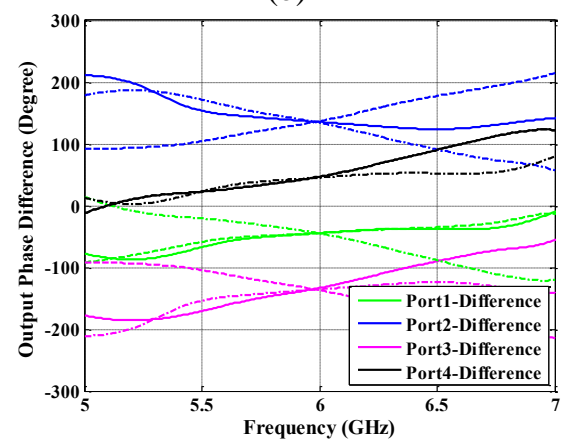

(c)

Figure 5: Reflection \& Transmission Coefficients When: (a) Port 1 and 3 excited (b) Port 2 and 4 excited, (c) Output Phase Differences (P1-P4) 




Figure 6: Photograph of the multibeam antenna array

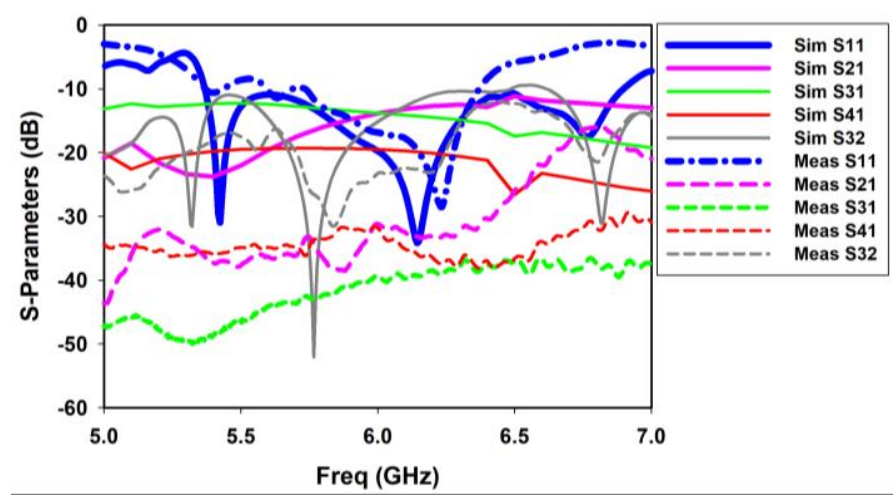

Figure 7. S-parameters of Multibeam Array

Hence very wide-angle maximum azimuthal scanning angle of $\pm 87^{\circ}$ with a 3 - $\mathrm{dB}$ scanning range of $\pm 120^{\circ}$ is achieved using a compact miniaturized multibeam array. Table II shows the simulated and measured beam positions of each beam.

TABle II: Simulated AND MEASUREd BEAM-Positions

\begin{tabular}{|l|c|c|c|c|c|}
\hline \multicolumn{2}{|c|}{ Port No. } & P1 & P2 & P3 & P4 \\
\hline $\begin{array}{l}\text { Beam } \\
\text { Position }\left(\theta^{\circ}\right)\end{array}$ & Simulated & $+87^{\circ}$ & $-20^{\circ}$ & $+20^{\circ}$ & $-87^{\circ}$ \\
\cline { 2 - 6 } & Measured & $+86^{\circ}$ & $-20^{\circ}$ & $+20^{\circ}$ & $-86^{\circ}$ \\
\hline \multicolumn{2}{|l|}{3 dB Beamwidth } & $71^{\circ}$ & $45.8^{\circ}$ & $44.4^{\circ}$ & $79.2^{\circ}$ \\
\hline
\end{tabular}

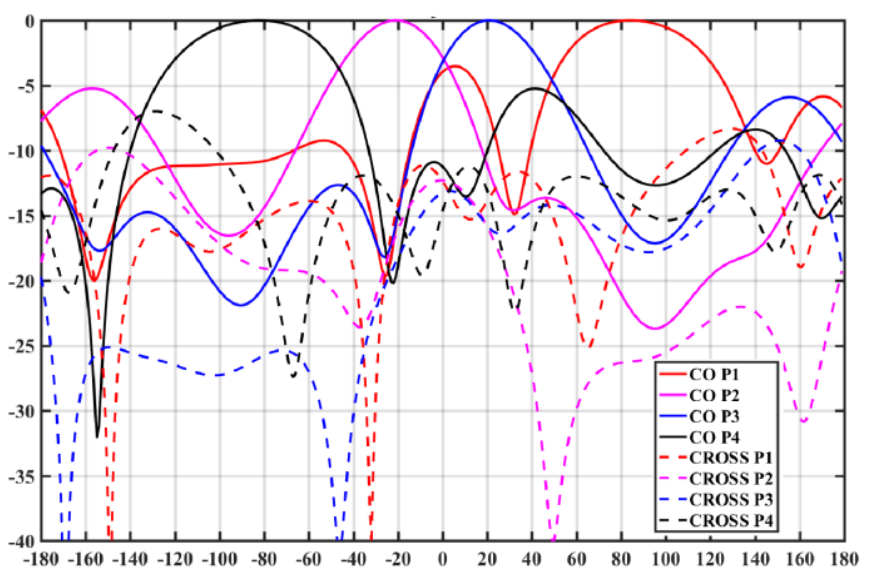

(a)

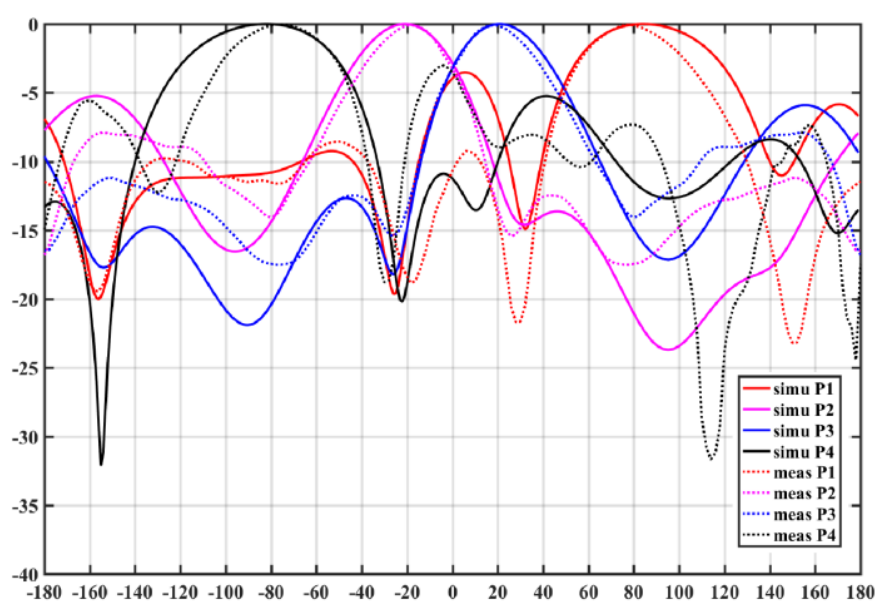

(b)

Figure 8. Multibeam capability (H-plane), (a) Simulated (b) Measured

\section{CONCLUSION}

This paper has presented a novel miniaturized compact multibeam wide-angle scanning PIEA array with a spacing of $0.3 \lambda$, designed, fabricated, and characterized for the $\mathrm{V} 2 \mathrm{X}$ applications. As a reduced array, inter-element spacing results in high mutual coupling and cross-polarization. Therefore to suppress mutual coupling and high cross-polarization, the design employs novel techniques that are: a compact PIEA designed with reduced width to accommodate an increased inter-corner spacing, the slots etched in between adjacent array elements and two decoupling meandered-line high impedance structures in these slots. This proposed PIEA array design is fed by a compact miniaturized 4x4 Butler Matrix. BM is designed without using phase shifters and conventional crossover. A slotcouple line is designed as a substitution of classical crossovers. With these techniques, when the compact multibeam array is developed, the far beams were successfully achieved, for the first time at $\pm 87^{\circ}$, with a 3 -dB beam scanning range of $\pm 120^{\circ}$. Multibeam array produced four beams at $-87^{0},-20^{\circ},+20^{\circ}$, and $+87^{\circ}$. The wide-angle scanning array design can be used as a phased array by using phase shifters to achieve a continuous 3$\mathrm{dB}$ scanning range of $240^{\circ}\left( \pm 120^{\circ}\right)$ and can be scaled to $\mathrm{mm}-$ wave.

\section{ACKNOWLEDGEMENT:}

This work was jointly supported in part by the Deanship of Scientific Research, Islamic University of Madinah, Grant No. 16/40, Tertiary Education Trust Fund, Nigeria, Universiti Teknologi Malaysia, and the Institute of Electronics and Telecommunications of Rennes (IETR), University of Rennes I, France.

\section{REFERENCES}

[1] L. Huang and Y. Lu, "A Switchable or MIMO Antenna for V2X Communication," in 2019 IEEE International Conference on Computational Electromagnetics (ICCEM), 
[2] S. Chen et al., "Vehicle-to-Everything (v2x ) Services Supported by LTE-Based Systems and 5G," IEEE Commun. Stand. Mag., no. June, pp. 70-76, 2017, doi: 10.1109/MCOMSTD.2017.1700015.

[3] A. Nasr, K. Sarabandi, and M. Takla, "Multi-beam DualPolarized Windshield Antenna with Wide Elevation Coverage for 5G V2X Applications," 2020 IEEE Int. Symp. Antennas Propag. North Am. Radio Sci. Meet. IEEECONF 2020 - Proc., pp. 1333-1334, 2020,

[4] Rabinovich, V. and N. Alexandrov, Antenna Arrays and Automotive Applications, Springer, New York, 2013

[5] T. Djerafi and K. Wu, "A low-cost wideband 77-GHz planar butler matrix in SIW technology," IEEE Trans. Antennas Propag., vol. 60, no. 10, pp. 4949-4954, 2012.

[6] C. Tsokos et al., "Analysis of a Multibeam Optical Beamforming Network Based on Blass Matrix Architecture," J. Light. Technol., vol. 36, no. 16, pp. 3354-3372, 2018.

[7] Y. Gao, M. Khaliel, F. Zheng, and T. Kaiser, "Rotman Lens Based Hybrid Analog-Digital Beamforming in Massive MIMO Systems: Array Architectures, Beam Selection Algorithms and Experiments," IEEE Trans. Veh. Technol., vol. 66, no. 10, pp. 9134-9148, 2017.

[8] N. J. G. Fonseca and N. Ferrando, "Nolen matrix with tapered amplitude law for linear arrays with reduced sidelobe level," in EuCAP 2010 - The 4th European Conference on Antennas and Propagation, 2010.

[9] S. Aliyubabale, S. H. Lawan, S. K. A. Rahim, and S. Ifeomaorakwue, "Implementation of $4 \times 4$ butler matrix using silver-nono instant inkjet printing technology," in 2017 IEEE 3rd International Conference on Electro-Technology for National Development, NIGERCON 2017, 2018, vol. 2018-Janua, pp. 514-518

[10] Q. L. Yang, Y. L. Ban, K. Kang, C. Y. D. Sim, and G. Wu, "SIW Multibeam Array for 5G Mobile Devices," IEEE Access, vol. 4, pp. 2788-2796, 2016.

[11] C. Bartlett and J. Bornemann, "Cross-Configuration Substrate Integrated Waveguide Beamforming Network for 1D and 2D Beam Patterns," IEEE Access, 2019.

[12] S. A. Babale et al., "Miniaturized Butler Matrix Beamforming Network Using 3dB Non-Standard Couplers," Zaria J. Electr. Eng. Technol. Dep. Electr. Eng. Ahmadu Bello Univ. Zaria Niger., vol. 9, no. 2, pp. pp11-15.

[13] S. I. Orakwue, R. Ngah, O. Elija, and S. A. Babale, "Cascaded Butler Matrix with Two-Dimensional Beam Scanning Capability at $28 \mathrm{GHz}$ for 5G Wireless System," Adv. Sci. Lett., 2018.

[14] J. Nasir, M. H. Jamaluddin, M. R. Kamarudin, I. Ullah, Y. C. Lo, and R. Selvaraju, "A Four-Element Linear Dielectric Resonator Antenna Array for Beamforming Applications with Compensation of Mutual Coupling," IEEE Access, vol. 4, no. October, pp. 6427-6437, 2016.

[15] M. K. Ishfaq et al., "Compact Four-Element Phased Antenna Array for 5G Applications," IEEE Access, vol. 7, pp. 161103 $161111,2019$.

[16] X. Ding, B.-Z. Wang and G.-Q. He, "Research on a MillimeterWave Phased Array with Wide-Angle Scanning Performance," IEEE Trans. Antennas Propag., vol. 61, no. 10, pp. 5319-5324, Oct. 2013.

[17] Y. Wang, L. Zhu, H. Wang, Y. Luo, and G. Yang, "A Compact, Scanning Tightly Coupled Dipole Array With Parasitic Strips For Next-Generation Wireless Applications," IEEE Antennas Wirel. Propag. Lett., vol. 1225, no. c, pp. 1-1, 2018, doi: 10.1109/LAWP.2018.2798660.
[18] M. Kamran Ishfaq, T. Abdul Rahman, H. T. Chattha, and M. Khalily, "A Novel Millimeter-Wave Linear PIFA Array Antenna for 5G Next Generation Wireless Communication System," 1st ICRIL-International Conference on Innovation in Science and Technology (IICIST 2015), April, pp. 664-668, 2015.

[19] Shuai Zhang, S. N. Khan, and S. He, "Reducing Mutual Coupling for an Extremely Closely-Packed Tunable Dual-Element PIFA Array Through a Resonant Slot Antenna Formed In-Between," IEEE Trans. Antennas Propag., vol. 58, no. 8, pp. 2771-2776, Aug. 2010, doi: 10.1109/TAP.2010.2050432.

[20] S. A. Babale, S. K. Abdul Rahim, O. A. Barro, M. Himdi, and M. Khalily, "Single Layered $4 \times 4$ butler matrix without phaseshifters and crossovers," IEEE Access, vol. 6, pp. 77289-77298, 2018.

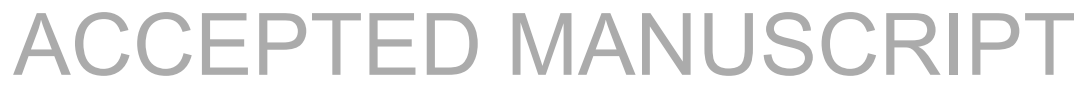

